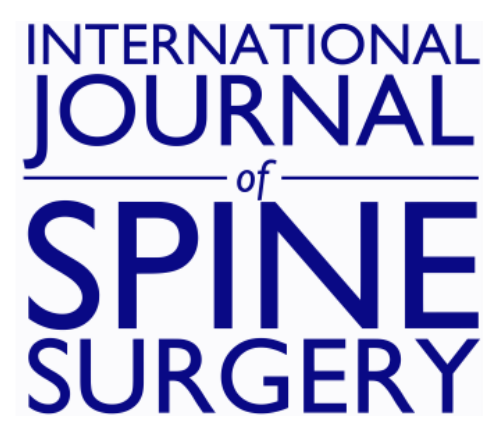

\title{
A Prospective Analysis of the Supine and Sitting Straight-Leg Raise Test and Its Performance in Litigation Patients
}

OLUKEMI K. FAJOLU, FABIO J. R. PENCLE, SAMUEL ROSAS and KINGSLEY R. CHIN

Int J Spine Surg 2018, 12 (1) 58-63

doi: https://doi.org/10.14444/5010

http://ijssurgery.com/content/12/1/58

This information is current as of April 26, 2023.

Email Alerts Receive free email-alerts when new articles cite this article. Sign up at:

http://ijssurgery.com/alerts

The International Journal of Spine Surgery

2397 Waterbury Circle, Suite 1,

Aurora, IL 60504, Phone: +1-630-375-1432 


\title{
A Prospective Analysis of the Supine and Sitting Straight- Leg Raise Test and Its Performance in Litigation Patients
}

\author{
OLUKEMI K. FAJOLU, MD, ${ }^{1}$ FABIO J. R. PENCLE, MB, BS, ${ }^{1}$ SAMUEL ROSAS, MS, ${ }^{1}$ KINGSLEY R. CHIN, \\ $\mathrm{MD}^{2-5}$ \\ ${ }^{1}$ Less Exposure Surgery (LES) Society, Fort Lauderdale, Florida ${ }^{2}$ Herbert Wertheim College of Medicine at Florida International University, Miami, Florida \\ ${ }^{3}$ Charles E. Schmidt College of Medicine at Florida Atlantic University, Boca Raton, Florida, ${ }^{4}$ Less Exposure Surgery Specialists (LESS) Institute, Fort \\ Lauderdale, Florida, ${ }^{5}$ University of Technology, Kingston, Jamaica
}

\begin{abstract}
Background: The supine straight-leg raise (SLR) test has the potential to be exploited by malingering patients. The sitting SLR is believed to be less recognizable, therefore decreasing the chance of fabrication. The authors aim to compare the supine and sitting SLR test in patients with radiculopathy.

Methods: A total of 107 patients with radiculopathy were included in this study. Two groups were created: patients with workman's compensation (Group 1) and a control group of patients without litigation claims (Group 2).

Results: Mean age was $47.3 \pm 1.3$ years with a $51 \%$ female population. Correlation analysis demonstrated association between mean angles in both positions, $r=0.248$ with significance $P=.01$. There was equivalence in the mean angles in sitting position of $37 \pm 3^{\circ}$ compared to $35 \pm 2^{\circ}$ in supine position $(P=.549)$. There was no significant difference in the mean angle at which the test became positive in the litigation group in the sitting or supine position compared to the nonlitigation group, $P=.616$ and $P=.49$ respectively.

Conclusion: This study demonstrated that the SLR test is equivalent in the sitting and supine position. Therefore, patients with a positive test should have similar angles in both positions, decreasing the chance of falsifying the examination.

Level of Evidence: Prospective analysis.

Clinical Relevance: Clinical practice.
\end{abstract}

Cervical Spine

Keywords: straight-leg raise, radiculopathy, sitting and supine position, workman's compensation, herniated disc, equivalence

\section{INTRODUCTION}

Radiculopathy and low back pain are often indications of mechanical compression around the lumbar nerve roots, such as in the presence of a herniated disc (HNP). One criterion for determining the presence and location of this compression is to perform a straight-leg raise (SLR) test. ${ }^{1-10}$ An accurate, positive SLR test exists when the patient is supine and the angle of discomfort is between 30 and $70^{\circ} .{ }^{10}$

The SLR test is used in routine neurological evaluations to test for low back pain or radiculopathy, and a positive result in the presence of a compressive lesion, such as a HNP, may lead to surgery. ${ }^{11-13}$ Anatomically, when the SLR is performed, the L5 and S1 nerve roots either move or passively deform approximately 2 to $6 \mathrm{~mm}$ at the level of the foramina. ${ }^{10}$ Therefore, it is believed that this test is most useful in detecting lower lumber root irritations. Patients are believed to experience sciatic pain when the sciatic nerve is stretched during the sitting and supine SLR exam. ${ }^{10}$

The supine SLR test is thought to be more commonly recognized by patients versus the sitting SLR test. As such, those patients seeking disability or undergoing litigation for workman's compensation or a motor vehicle accident may imitate a positive supine SLR test for compensation purposes. In order to test whether or not the patient is falsifying a complaint, Waddell et al. ${ }^{14}$ established 5 tests which have been assessed and confirmed by several studies. ${ }^{15-18}$ In one of their tests, the physician distracts the patient while performing both the sitting and supine version of the SLR test to see if the results are the same. ${ }^{10,14}$ This test was based on the premise that the results of either the 


\begin{tabular}{lc} 
Table 1. Demographic data of patients with radiculopathy $(\mathrm{N}=107)$. \\
\hline Age & $\mathrm{N}=107(\%)$ \\
$18-39$ & $33(31 \%)$ \\
$40-64$ & $65(61 \%)$ \\
$>65$ & $9(8 \%)$ \\
Gender & $\mathrm{N}=107(\%)$ \\
Male & $52(49 \%)$ \\
Female & $55(51 \%)$ \\
Cohort groups & $\mathrm{N}=107(\%)$ \\
Non WC & $82(77 \%)$ \\
WC & $25(23 \%)$ \\
Diagnosis HNP & $\mathrm{N}=98(\%)$ \\
Non-WC & $79(81 \%)$ \\
WC & $19(19 \%)$ \\
\hline
\end{tabular}

Abbreviations: HNP, herniated disc; WC, workman's compensation.

sitting or the supine SLR test would be equivalent if the patient is not falsifying complaints.

We are not aware, however, of any prospective study that has validated this practice and determined if the sitting and supine SLR tests yield equivalent results. The purpose of this prospective study was to compare the supine and sitting SLR test in patients during routine neurological evaluations. We hypothesized that the results of the sitting SLR test would be equivalent to the supine SLR test and that patients would have a positive SLR test at similar angles during both examinations.

\section{METHODS}

The Institutional Review Board at our institution granted permission for this study. Participants enrolled in this SLR study were consecutive patients who presented to our spine clinic complaining of low back pain and/or radiculopathy. There were 110 participants enrolled in the study. One hundred seven patients had a positive clinical examination of radiculopathy; the other 3 had only back pain. The 3 patients with back pain without radiculopathy were excluded from this study as they did not fit the inclusion criteria during clinical examination.

Two groups were then created: patients with worker's compensation claims or litigation (Group 1 , also referred to as the WC group) consisting of 25 patients and a control group of patients without involvement in litigation claims (Group 2, also referred as the non-WC group) comprising 82 patients. Patient's demographics are demonstrated in Table 1.

Patients presented to the spine clinic with HNPs, radiculopathy, and spondylolisthesis. We were particularly interested in the diagnosis of HNPs (Table 1). For each patient, documentation of

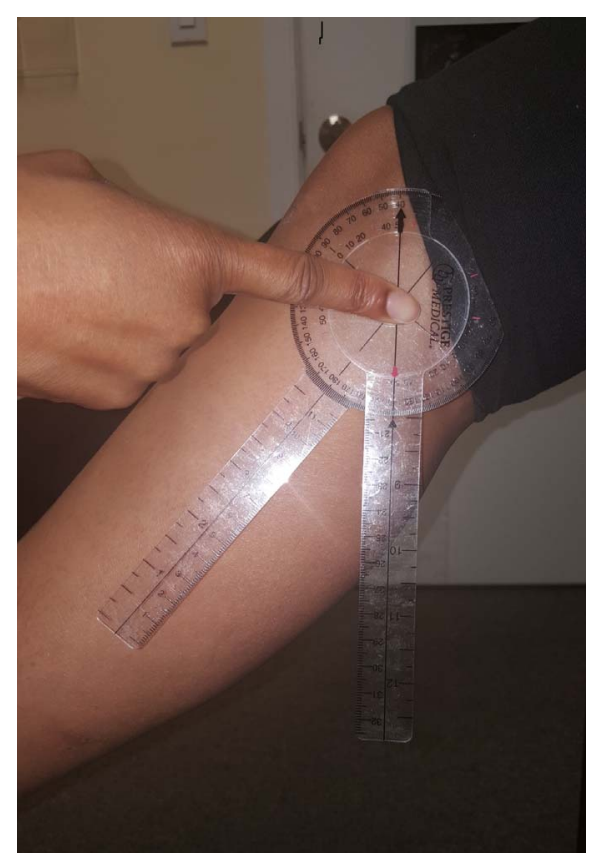

Figure 1. Technique of measuring straight-leg raise in sitting position.

whether or not patients were filing for workman's compensation or were involved in litigation over an injury was done by intake staff. Physicians were blinded to payment method. Patients were not asked about prior knowledge of SLR tests to minimize confirmation bias.

\section{Assessment of Radiculopathy}

All patients were blinded to the study outcome variables. To decrease variability, all SLR angles were measured using a transparent goniometer (Hanger Prosthetics \& Orthotics, Houston, Texas) by the same physician.

The angles for the sitting SLR were performed and measured first on each patient in each leg before the supine measurements. Patients were not asked if they experienced any symptoms while performing the tests to avoid prompting new patient complaints. The sitting SLR tests were performed with the patient's legs hanging over the side of the examination table and hips and knees naturally flexed at $90^{\circ}$. The patient's leg was then passively and gently lifted by the examining physician while observing that the patient did not tilt posteriorly to ensure the patient's back was upright until the patient complained of any pain. We made note of whether the pain was low back, buttock, and/or radicular pain. At the moment a complaint was made, we measured and recorded the angle between the patient's leg and a perpendicular line to the 


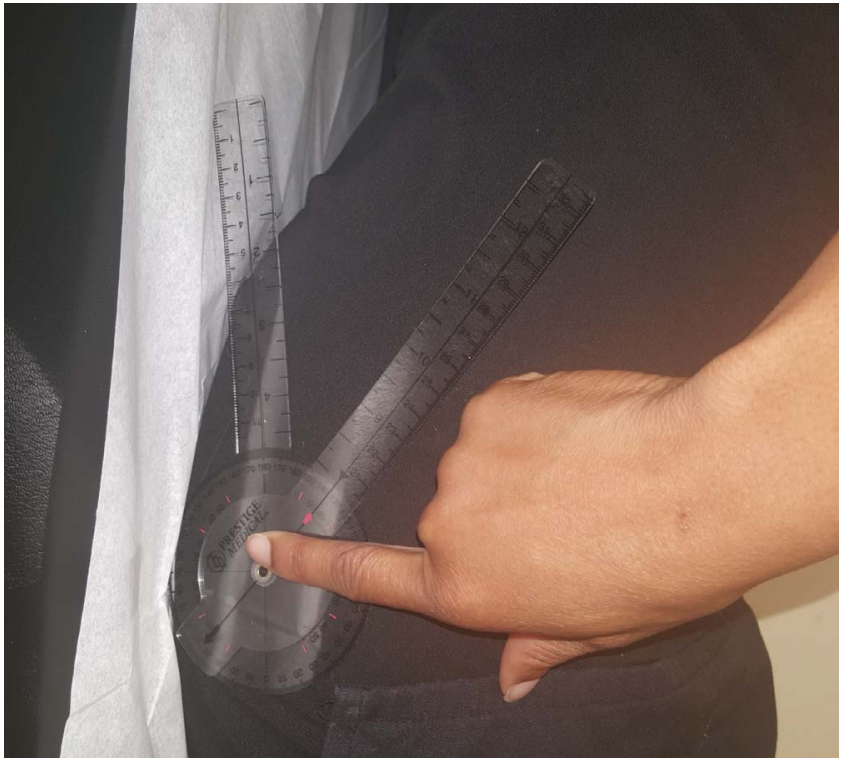

Figure 2. Technique of measuring straight-leg raise in supine position.

floor, as well as the location of the pain (Figure 1). ${ }^{8}$ We ensured that, during measurement, the patient's back was straight and the patient did not roll to the affected side. During the supine SLR tests, patients lay on their backs with their hips and knees flat on the table. Each leg was passively and gently raised and flexed at the hip by the same examining physician with his hand beneath the heel, while keeping the knee straight. When the patient complained of low back, buttock, and/or radicular pain down the legs, the angle of hip flexion as well as the location of the pain was recorded (Figure 2). ${ }^{3}$ This was also confirmed clinically by the examiner flexing the knee at this angle to check for relief or if the patient still complained of pain. ${ }^{19}$ Patients with negative SLR tests in both sitting and supine positions (3 patients) and those patients who had previous hip or spine contractures (15 patients not enrolled) were excluded from the study. Patients with sciatic complaints referable to nerve roots from L4 to S1 were included. A negative SLR was recorded with any angle measured as $\geq 75^{\circ} .{ }^{10}$

\section{Bar graph of mean angles}

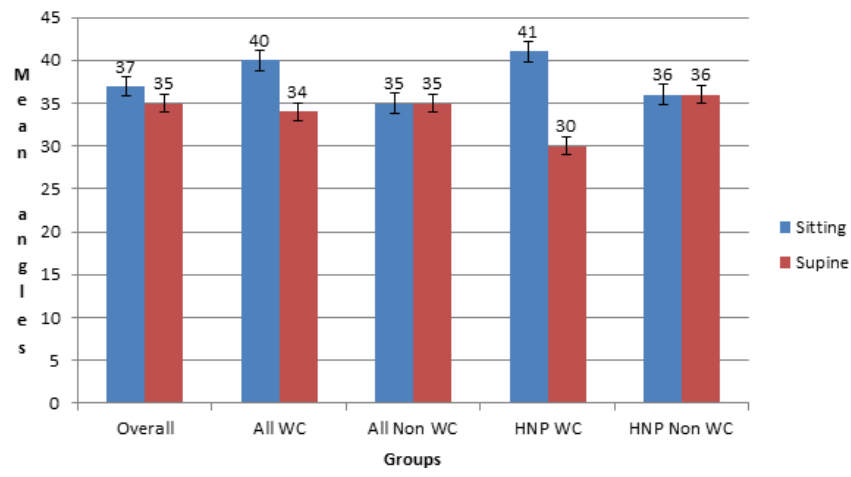

Figure 3. Graph depicting angles in each group in sitting and supine positions. Abbreviations: HNP, herniated disc; WC, workman's compensation.

\section{Statistical Analysis}

Correlation analysis using linear regression was performed to determine if mean angles of all patients with positive sciatica in the sitting position demonstrated any association with mean angles in the supine position. Further testing to determine if mean angles were equivalent using $t$ tests was then performed. Intergroup comparison was then performed for age and gender using $t$ tests and $\chi^{2}$, respectively, to determine baseline characteristics as nonconfounding variables. Tests were considered significant if $P$ values were less than .05 . A power analysis was performed based on equivalence to determine adequate sample size. To achieve a power of 0.8 and error rate of $5 \%$, a minimum sample size of 72 was required. ${ }^{20,21}$

\section{RESULTS}

There were a total of 107 patients with radiculopathy with an overall age of $47.3 \pm 1.3$ years with $51 \%$ female population. The mean \pm standard error of the mean age of male participants was $43.8 \pm 1.9$ years and of female participants was $50.7 \pm 1.8$ years.

Correlation analysis demonstrated association between mean angles in the sitting and supine positions, $r=0.248$ with significance $P=.01$.

Table 2. Straight-leg raise mean angles and respective $P$ values.

\begin{tabular}{|c|c|c|c|c|c|c|c|}
\hline & \multirow[b]{2}{*}{ Overall } & \multicolumn{2}{|c|}{ All Diagnoses } & \multirow[b]{2}{*}{ Intergroup $P$ Value } & \multicolumn{2}{|c|}{ HNP } & \multirow[b]{2}{*}{ Intergroup $P$ Value } \\
\hline & & WC & Non-WC & & WC & Non-WC & \\
\hline Sitting & $37 \pm 3$ & $40 \pm 7$ & $35 \pm 3$ & .616 & $41 \pm 7$ & $36 \pm 4$ & .284 \\
\hline Supine & $35 \pm 2$ & $34 \pm 5$ & $35 \pm 2$ & .49 & $30 \pm 4$ & $36 \pm 3$ & .702 \\
\hline Intragroup $P$ value & .549 & .432 & .54 & & .08 & .93 & \\
\hline
\end{tabular}

Abbreviations: HNP, herniated disc; WC, workman's compensation. 
Table 3. Mean age, gender distribution, and patients with radiculopathy with respective $P$ values.

\begin{tabular}{lccc}
\hline & WC & Non-WC & $\boldsymbol{P}$ Value \\
\hline Age & $46 \pm 2$ & $48 \pm 2$ & .330 \\
Female & 10 & 45 & .254 \\
Male & 15 & 37 & .254 \\
\hline
\end{tabular}

Abbreviation: WC, worker's compensation.

Equivalence was demonstrated between the mean angles in the sitting position of $37 \pm 3^{\circ}$ compared to $35 \pm 2^{\circ}$ in the supine position (Figure 3), $P=.549$ shown in Table 2. Comparison was then performed between Group 1 (the WC group) and Group 2 (non-WC). The mean age in the WC group was 46 \pm 2 years, and $48 \pm 2$ years in the non-WC group, which was not significantly different, $P=.330$ (Table 3). The gender distribution in the WC group was $40 \%$ female and $60 \%$ male, while in the nonWC group, it was $54 \%$ female and $46 \%$ male. The gender distributions proved not to be statistically significant, $P=.254$ shown in Table 3 . These 2 variables proved that both groups had similar baseline characteristics, which allowed for their comparison without the confounders of age or gender.

Overall mean angle (Table 2) in Group 1 in the sitting position was $40 \pm 7^{\circ}$ compared to Group 2, which was $35 \pm 3^{\circ}, P=.616$. In the supine position, Group 1 angles were $34 \pm 5^{\circ}$ compared to $35 \pm 2^{\circ}$ in Group 2, $P=.49$. Results demonstrated no statistical significance between angles in both groups

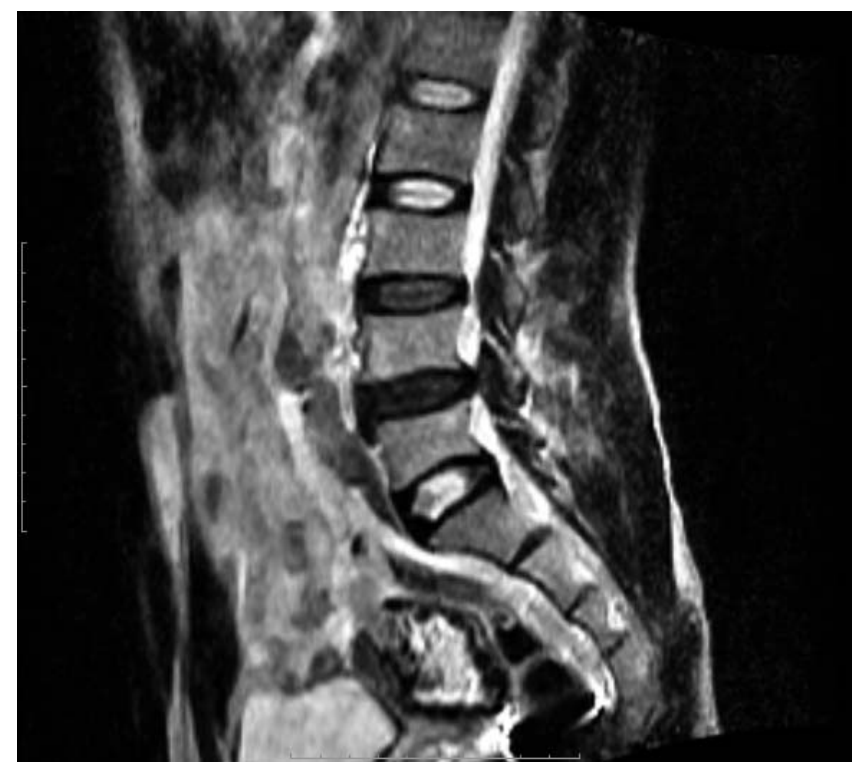

Figure 4. Sagittal magnetic resonance imaging demonstrating herniated disc at L4-5, L5-S1. in sitting or supine positions. Equivalence was then tested in each group between the sitting and supine positions (Figure 3). Group 1 mean sitting angle was $40 \pm 7^{\circ}$ compared to $34 \pm 5^{\circ}$ in the supine position, $P=.432$. In Group 2, mean sitting angle was $35 \pm$ $3^{\circ}$ compared to $35 \pm 2^{\circ}$ in the supine position, $P=$ .54 shown in Table 2 .

\section{Effects of Diagnoses}

We were especially interested in comparing the 98 $(92 \%)$ patients who were diagnosed with HNPs (Figure 4) because the SLR test is thought to be particularly helpful in making this diagnosis. Nineteen patients from Group 1 were noted to have HNPs and 79 from Group 2; Z score was 0.61 with $P=.271$, which demonstrated no significance between the mean scores in each group. The mean angles in Group 1 were $41 \pm 7^{\circ}$ in the sitting position and $30 \pm 4^{\circ}$ in the supine position compared to Group 2 angles of $36 \pm 4^{\circ}$ in the sitting position and $36 \pm 3^{\circ}$ in the supine position, $P$ $=.284$ and $P=.702$, respectively. Intragroup equivalence testing also demonstrates no significance between sitting and supine angles in the HNP WC group and the HNP non-WC group, $P=.08$ and $P=.93$, respectively. Results are demonstrated in Table 2.

\section{DISCUSSION}

The SLR test has been accepted as the most consistent test for applying tension to the nerve root, eliciting a physical sign that is used to aid in the diagnosis of low back pain and radiculopathy. ${ }^{22-24}$ The ease and reproducibility of performing the SLR test by physicians has therefore shown its merits. Studies have confirmed that the SLR test is reproducible during unilateral and bilateral maneuvers. ${ }^{25-27}$ A study by Hunt et al., ${ }^{28}$ however, has shown the SLR and lumbar ranges of motion tests have not been reliable. Their study has some discrepancies in that measurements were performed by multiple examiners on separate days, and the test subjects were volunteers without pathology. Our study aimed to reduce these confounding factors using 1 examiner and not prompting patients with pathology, increasing the reliability of measurements recorded. Patients were blinded to the difference of each test and its clinical significance. 


\section{Discussion of Results}

The purpose of this prospective study was to compare the supine and sitting SLR test in patients during routine neurological evaluations. Initial testing demonstrates that the sitting and supine SLR are associated based on significance testing. The low correlation coefficient is due to wide distribution around a fitted line plot. Based on our hypothesis, we have demonstrated that the angle at which patients complained of positive radiculopathy showed no significant difference between the supine and sitting SLR examinations. We have also proven the equivalence in the SLR test in both the supine and sitting positions, $P=.549$. This has demonstrated that patients who have positive radiculopathy should have similar angles in each test, thus reducing the possibility of patients falsifying clinical examinations. When we compared our WC patients and non-WC patients, the angles at which patients complained of a positive test showed no significance between the groups. Likewise, the vast majority of our patients $(92 \%)$ who presented with HNPs showed no significant difference in the sitting and supine positions.

\section{Strengths}

The authors report no conflicts of interest and observer bias limited by physicians and patients blinded to payment method and outcomes, respectively. This study assesses clinically the sitting and supine SLR as it relates to equivalence and patients who present with radiculopathy to a spine clinic. The study had an adequate sample population based on power analysis which was assessed by an independent statistician. In measuring the SLR, each patient was not prompted, and all angles were measured by the same physician to reduce examiner difference.

\section{Limitations and Weakness}

Limitations of this study include a single center review for patients who presented with back pain. The authors note a weakness in that the cohort groups were not equal; however, being a prospective study, the selection of patients was not predetermined. A larger power $(\mathrm{N})$ was noted in the nonWC group, both in all diagnoses and the HNP subset. However, no intergroup or intragroup significance was demonstrated. Looking at the diagnosis of $\mathrm{HNP}$ and $\mathrm{WC}$, the mean difference of $11^{\circ}$, although not statistically significant, warrants further study as this may be clinically significant.

\section{CONCLUSION}

Our results demonstrate that the sitting and supine SLR tests are equivalent examinations. The majority of our patients experiencing a positive supine SLR also recorded a positive sitting SLR. In cases with both positive supine and sitting SLR tests, the majority of our patients experienced pain at similar angles when sitting and supine.

\section{REFERENCES}

1. Deville WL, van der Windt DA, Dzaferagic A, Bezemer PD, Bouter LM. The test of Lasegue: systematic review of the accuracy in diagnosing herniated discs. Spine. 2000;25(9):1140 1147.

2. Gajdosik RL, Rieck MA, Sullivan DK, Wightman SE. Comparison of four clinical tests for assessing hamstring muscle length. J Orthop Sports Phys Ther. 1993;18(5):614-618.

3. Hanten WP, Chandler SD. Effects of myofascial release leg pull and sagittal plane isometric contract-relax techniques on passive straight-leg raise angle. J Orthop Sports Phys Ther. 1994;20(3):138-144.

4. Hsieh CY, Walker JM, Gillis K. Straight-leg-raising test. Comparison of three instruments. Phys Ther. 1983;63(9):14291433.

5. Hunt DG, Zuberbier OA, Kozlowski AJ, et al. Reliability of the lumbar flexion, lumbar extension, and passive straight leg raise test in normal populations embedded within a complete physical examination. Spine. 2001;26(24):2714-2718.

6. Lew PC, Morrow CJ, Lew AM. The effect of neck and leg flexion and their sequence on the lumbar spinal cord. Implications in low back pain and sciatica. Spine. 1994;19(21):2421-2424; discussion 2425.

7. Mens JM, Vleeming A, Snijders CJ, Koes BW, Stam HJ Validity of the active straight leg raise test for measuring disease severity in patients with posterior pelvic pain after pregnancy. Spine. 2002;27(2):196-200.

8. Meszaros TF, Olson R, Kulig K, Creighton D, Czarnecki E. Effect of $10 \%, 30 \%$, and $60 \%$ body weight traction on the straight leg raise test of symptomatic patients with low back pain. J Orthop Sports Phys Ther. 2000;30(10):595-601.

9. Vroomen PC, de Krom MC, Wilmink JT, Kester AD, Knottnerus JA. Diagnostic value of history and physical examination in patients suspected of lumbosacral nerve root compression. J Neurol Neurosurg Psychiatry. 2002;72(5):630 634.

10. Fardon DF, Society NAS, eds. Orthopaedic Knowledge Update: Spine 2. Rosemont, IL: American Academy of Orthopaedic Surgeons; 2002.

11. Chin KR, Tomlinson DT, Auerbach JD, Shatsky JB, Deirmengian CA. Success of lumbar microdiscectomy in patients with modic changes and low-back pain: a prospective pilot study. J Spinal Disord Tech. 2008;21(2):139-144.

12. Chin KR, Sundram H, Marcotte P. Bleeding risk with 
ketorolac after lumbar microdiscectomy. J Spinal Disord Tech. 2007;20(2):123-126.

13. Chin KR, Michener TA. Prospective evaluation of a 3blade speculum cannula for minimally invasive lumbar microdiscectomy. J Spinal Disord Tech. 2006;19(4):257-261.

14. Waddell G, McCulloch JA, Kummel E, Venner RM. Nonorganic physical signs in low-back pain. Spine. 1980;5(2):117-125.

15. Blom A, Taylor A, Whitehouse S, Orr B, Smith E. A new sign of inappropriate lower back pain. Ann $R$ Coll Surg Engl. 2002;84(5):342-343.

16. Manchikanti L, Fellows B, Singh V, Pampati V. Correlates of non-physiological behavior in patients with chronic low back pain. Pain Physician. 2003;6(2):159-166.

17. Apeldoorn AT, Ostelo RW, Fritz JM, van der Ploeg T, van Tulder MW, de Vet HC. The cross-sectional construct validity of the Waddell score. Clin J Pain. 2012;28(4):309-317.

18. Main CJ, Waddell G. Behavioral responses to examination: a reappraisal of the interpretation of "nonorganic signs". Spine. 1998;23(21):2367-2371.

19. Westbrook A, Tambe A, Subramanian K, Monk J, Calthorpe D. The mannequin sign. Spine. 2005;30(5):E115E117.

20. Suresh K, Chandrashekara S. Sample size estimation and power analysis for clinical research studies. J Hum Reprod Sci. 2012;5(1):7-13.

21. Carneiro AV. Estimating sample size in clinical studies: basic methodological principles. Rev Port Cardiol. 2003;22(12):1513-1521.

22. Charnley J. Orthopaedic signs in the diagnosis of disc protrusion. With special reference to the straight-leg-raising test. Lancet (London, England). 1951;1(6648):186-192.

23. Smith SA, Massie JB, Chesnut R, Garfin SR. Straight leg raising. Anatomical effects on the spinal nerve root without and with fusion. Spine. 1993;18(8):992-999.

24. Jonsson B, Stromqvist B. The straight leg raising test and the severity of symptoms in lumbar disc herniation. A preoperative evaluation. Spine. 1995;20(1):27-30.

25. Rade M, Shacklock M, Kononen M, et al. Part 3: Developing methods of in vivo MRI measurement of spinal cord displacement in the thoracolumbar region of asymptomatic subjects with unilateral and bilateral straight leg raise tests. Spine. 2015;40(12):935-941.

26. Rade M, Kononen M, Vanninen R, et al. 2014 young investigator award winner: in vivo magnetic resonance imaging measurement of spinal cord displacement in the thoracolumbar region of asymptomatic subjects: part 1: straight leg raise test. Spine. 2014;39(16):1288-1293.

27. Rade M, Kononen M, Vanninen R, et al. 2014 young investigator award winner: in vivo magnetic resonance imaging measurement of spinal cord displacement in the thoracolumbar region of asymptomatic subjects: part 2: comparison between unilateral and bilateral straight leg raise tests. Spine. 2014;39(16):1294-1300.

28. Hunt DG, Zuberbier OA, Kozlowski AJ, et al. Reliability of the lumbar flexion, lumbar extension, and passive straight leg raise test in normal populations embedded within a complete physical examination. Spine. 2001;26(24):2714-2718.

Disclosures and COI: We did not seek or receive any funding from the National Institutes of Health (NIH), Wellcome Trust, Howard Hughes Medical Institute (HHMI), or others for this work. $\mathrm{KRC}$ is a shareholder in and receives other benefits from SpineFrontier Inc. None of the other authors (OKF, FJRP, and SR) have any potential conflicts of interest to declare for this work. Institutional review board approval was obtained and approved to conduct this study.

Corresponding Author: Kingsley R. Chin, MD, Less Exposure Surgery Specialists Institute (LESS Institute), 3816 Hollywood Blvd., Ste. 102, Hollywood, FL 33021. Phone: (954) 640-6010; Fax: (855)411-4647; Email: kingsleychin@, thelessinstitute.com.

Published 30 March 2018

This manuscript is generously published free of charge by ISASS, the International Society for the Advancement of Spine Surgery. Copyright (C) 2018 ISASS. To see more or order reprints or permissions, see http://ijssurgery.com. 